\title{
Miriam Hansen e as contribuições da Escola de Frankfurt para a teoria do cinema
}

\section{Miriam Hansen and the Frankfurt School's contributions to film theory}

Otávio Daros ${ }^{1}$ 


\section{Resumo}

Historiadora do cinema, Miriam Hansen examinou e sistematizou as contribuições de Siegfried Kracauer, Walter Benjamin e Theodor Adorno para a teorização do cinema. Nesta pesquisa bibliográfica, buscamos sintetizar e apresentar aos leitores de língua portuguesa o desenvolvimento de sua investigação sobre o tema. Mostramos como Hansen foi capaz de identificar as principais diferenças entre os teóricos frankfurtianos, bem como evidenciar que eles, em comum, pensaram este fenômeno cultural contemporâneo em relação às condições sociais e econômicas de produção. Em suas reflexões, o cinema aparece como expressão da sociedade urbano-industrial, como um elemento sintomático da cultura de massa.

\section{Palavras-chave}

Teoria do cinema, Escola de Frankfurt, Siegfried Kracauer, Walter Benjamin, Theodor Adorno.

\section{Abstract}

Film historian Miriam Hansen examined and systematized the contributions of Siegfried Kracauer, Walter Benjamin and Theodor Adorno according to the theorization of cinema. In this bibliographic research, we seek to synthesize and present to Brazilian Portuguese language readers the development of her research on the topic. We show how Hansen was able to identify the main differences between Frankfurt theorists, as well as to show that they, in common, thought about this contemporary cultural phenomenon in relation to the social and economic conditions of production. In their reflections, cinema appears as an expression of urban-industrial society, as a symptomatic element of mass culture.

\section{Keywords}

Film theory, Frankfurt School, Siegfried Kracauer, Walter Benjamin, Theodor Adorno. 


\section{Introdução}

Miriam Bratu Hansen (1949-2011) foi uma notável estudiosa da história do cinema teuto-americano, formada pela escola crítica alemã, entre as décadas de 1960 e 1970, mas que se fixou na universidade norte-americana desde os anos de 1990. Ficou reconhecida ali após a publicação de Babel and Babylon: Spectatorship in American Silent Film, em 1991. À luz das discussões frankfurtianas sobre indústria cultural e esfera pública, a autora mostrou como se deu o surgimento e a formação cultural do "espectador de cinema", na era de ouro de Hollywood.

Entretanto, não é essa, mas a última obra de Hansen que motiva esta investigação. Propomos nas páginas que seguem uma leitura de Cinema and Experience: Siegfried Kracauer, Walter Benjamin, and Theodor W. Adorno, publicado em 2011. No livro, Hansen oferece rica e densa matéria para quem se interessa pelo estudo do cinema a partir das perspectivas da Escola de Frankfurt, na medida em que ela oferece reflexão sistematizada sobre as contribuições dadas pelos três teóricos críticos, mencionados no título do material.

Nosso objetivo é rever a literatura frankfurtiana sobre cinema, conhecer as principais ideias de seus teóricos e, ao fim, analisar se há e quais são os pontos de aproximação e distanciamento entre eles. Fazemos isso amparados na pesquisa de Hansen, uma vez que é nosso objetivo entender como a autora, na posição de estudiosa de ambos, julga as contribuições da escola alemã para a área:

\footnotetext{
Como legado para a teoria do cinema e do cinema no(s) limiar(es) atual(is) da cultura da imagem em movimento, não acho que esses escritores contribuam com novas ontologias. Eles estavam mais interessados no que o cinema faz, no tipo de experiência mimética sensorial-perceptiva que ele possibilitou, do que [em responder] o que é cinema. [...] Eles consideravam o cinema como parte de uma fenomenologia em evolução da modernidade, e o interesse deles era nas modalidades particulares do nexo entre a experiência do cinema e a experiência vivida pelo público espectador. (HANSEN, 2011, p. xvii, tradução nossa)
}

A respeito de Kracauer, a autora trabalha com os aspectos ligados à representação e experiência, e com sua proposta de teoria do filme. No que 
tange os ensaios de Benjamin, o fenômeno tecnológico e o conceito de aura são destacados ao longo da análise. E, por fim, sobre a obra de Adorno, ela se concentra sobretudo nas questões da estética e da técnica. Em linhas gerais, este é o percurso feito por Hansen em seu estudo.

\section{Siegfried Kracauer}

Entre os teóricos da primeira geração da Escola de Frankfurt, Siegfried Kracauer (1889-1966) é seguramente a figura mais comprometida com o estudo do cinema. Sua trajetória intelectual começa com trabalhos gerais de revisão e crítica, nos quais pensava o cinema combinado com outras artes (teatro, arquitetura etc.), em suas relações com as práticas cotidianas. A partir de 1925, como sinaliza Hansen, seu trabalho ganha progressivamente forma e conteúdo reflexivos, "Quando, ao final da década, seus escritos sobre filme e cinema mudaram cada vez mais de uma fisionomia materialista da modernidade para uma crítica da ideologia" (HANSEN, 2011, p. 6), a exemplo do livro From Caligari to Hitler (1947):

por trás da história aberta das mudanças econômicas, as exigências sociais e as maquinações políticas executam uma história secreta envolvendo as disposições internas do povo alemão. A exposição destas disposições através da tela alemã pode ajudar na compreensão da ascensão e ascendência de Hitler. (KRACAUER, 1947, p. 11)

O pensamento reflexivo de Kracauer se desenvolveu longe da academia, em um ambiente marcado pela pressão do imediatismo: em uma redação de jornal. "Entre 1921 e 1933, ano do seu exílio forçado, Kracauer publicou cerca de dois mil artigos - notícias, resenhas, ensaios - a maioria deles no Frankfurter Zeitung, um diário liberal do qual se tornou editor de folhetins (arte e cultura) em 1924".

Kracauer também havia trabalhado como arquiteto, antes de se dedicar à sessão de cultura e cotidiano desse jornal. Experiências que não devem ser apagadas de sua biografia, na medida que nos ajudam a entender porque Kracauer não se tornou um teórico sistemático como seus colegas do Instituto de Pesquisa Social, a exemplo de Adorno e Marcuse: 
Pelos padrões filosóficos, o modo de análise de Kracauer às vezes parece escorregadio e inconsistente, se não contraditório. Isso não é simplesmente ou necessariamente uma falha. Em vez disso, o que garante fascínio contínuo com os textos de Kracauer é que eles são trabalhados com outro tipo de lógica, um estilo de teorização que poderíamos chamar de autoral ou poético. (HANSEN, 2011, p. 5, tradução nossa)

A falta de formação acadêmica, entretanto, não significa que não houve formação do ponto de vista mais significativo: o intelectual. Kracauer esteve comprometido com a reflexão filosófica, sociológica, literária, embora não tenha investido na carreira universitária. Georg Simmel e Roland Barthes foram dois dos pensadores que o influenciaram fortemente:

O interesse de Kracauer pelos fenômenos cotidianos e efêmeros da vida moderna era, sem dúvida, devedor do filósofo-sociólogo Georg Simmel, mas sua exploração dos artefatos, locais e rituais de uma cultura de consumo emergente também aponta para análises semiológicas como as Mythologies (1957) de Roland Barthes, e trabalhos mais recentes sobre etnografia urbana e crítica da vida cotidiana. (HANSEN, 2011, p. 4, tradução nossa)

Este arcabouço teórico acaba por enriquecer suas reflexões sobre o cinema e a cultura de massa. Neste período, entre as décadas de 1920 e 1930, o filósofo começa a teorizar o cinema enquanto "o meio perfeito para um mundo decaído, um discurso sensorial e reflexivo único para captar a experiência de um mundo em desintegração" (HANSEN, 2011, p. 5, tradução nossa).

Neste estágio, a estudiosa ressalta o problema de Kracauer em relação à modernidade, a qual era vista por ele com pessimismo. Na visão dele, "a ideia escatologicamente tingida de que a modernidade poderia ser superada - e poderia se superar - apenas realizando plenamente todo o seu potencial desintegrador e destrutivo" (HANSEN, 2011, p. 5, tradução nossa).

Embora estivesse fundamentado em bases histórico-filosóficas, seu pensamento não deixava de representar uma "tentativa programática de compreender os fenômenos culturais contemporâneos em relação às condições sociais e econômicas que Ihes deram origem e às quais se pensava responder" (HANSEN, 2011, p. 3, 
tradução nossa). Há, nesse sentido, um esforço de Kracauer em conceber o "filme como uma expressão material - não apenas [como] representação - de uma experiência histórica particular, um correlato objetivo, por assim dizer, do processo em curso de desintegração" (HANSEN, 2011, p. 10, tradução nossa, grifo da autora).

Hansen chama atenção para o caminho intelectual que Kracauer percorreu, em um curto espaço de tempo, partindo de uma abordagem metafísica (desintegração do mundo como problema da modernidade) e voltando-se para uma atitude pós-metafísica: "mais sóbria, analítica, politicamente astuta e, no entanto, apaixonadamente curiosa em relação aos fenômenos concretos da vida moderna, em particular a cultura de massa" (HANSEN, 2011, p. 7, tradução nossa). Nesta mudança, o filósofo passa a valorizar o cinema enquanto "sintoma do processo histórico e do horizonte sensório-reflexivo" (HANSEN, 2011, p. 6, tradução nossa).

Os primórdios dessa transformação remontam à experiência da Primeira Guerra Mundial, que para Kracauer, como para muitos de sua geração, destruiu as ilusões do alto idealismo e lançou sua sombra monstruosa na década seguinte; não é coincidência que seu romance semiautobiográfico, Ginster, escrito no final da década de 1920, se passa durante a guerra e no período posterior. Portanto, a virada de Kracauer para uma perspectiva mais materialista não deve ser imaginada nem como uma conversão repentina nem como um desenvolvimento progressivo em direção a uma posição mais criticamente correta, mas como um processo de reorientação e complicação em que as perspectivas anteriores surgem e persistem, mesmo que incongruente, com as posteriores. (HANSEN, 2011, p. 7, tradução nossa)

Com o tempo, Kracauer desenvolve sua análise a partir de uma crítica marxista do capitalismo, mais interessada na ideologia do que na tecnologia. Se Kracauer, por um lado, compartilha o pressuposto marxista, por outro, distanciase de qualquer apropriação ortodoxa. Serve de prova disso: Kracauer investe em abordagem ligada à psicanálise, buscando ali (e não no âmbito marxista da superestrutura) as respostas para relacionar a produção fílmica aos "mecanismos ideológicos da consciência pública" (HANSEN, 2011, p. 51, tradução nossa).

Na visão dele, o cinema é "a instituição cultural mais avançada na qual as massas, como uma forma relativamente heterogênea, indefinida e ainda pouco 
compreendida de coletividade, constituem uma nova forma de público" (HANSEN, 2011, p. 54, tradução nossa, grifo da autora). Ou seja, para ele, o cinema serve de "modelo para uma esfera pública alternativa que só pode realizar-se através da destruição da esfera pública burguesa dominante, que extrai legitimação de instituições tradicionais de arte, educação e cultura que não estão mais em contato com a realidade" (HANSEN, 2011, p. 55, tradução nossa).

A teorização de Kracauer está em interação, em constante movimento de aproximação e afastamento, com as ideias de indústria cultural de Horkheimer e Adorno (1985), com o ensaio sobre tecnologia e obra de arte de Benjamin e, posteriormente, com o conceito de esfera pública de Habermas. Em outras palavras, trata-se de um movimento de interação com a teoria crítica, muito mais do que uma apropriação fechada de seus teóricos.

\footnotetext{
Por um lado, Kracauer não condena a mercantilização, a produção em série e a padronização como tal, como pode ser visto em suas muitas resenhas positivas de fiç̧ão popular, especialmente romances de detetive e aventura, bem como em suas repetidas, embora às vezes relutantes, declarações de admiração por Hollywood sobre os produtos UfA [Universum Film Aktien Gesellschaft]. Por outro lado, Kracauer não presumiria que as pessoas que assistiam à mesma coisa estavam pensando da mesma maneira; e se elas padronizam sua aparência e comportamento nas figuras e nas fábulas da tela, o problema estava principalmente na circulação da ideologia escapista na tela pela indústria cinematográfica alemã e na gentrificação compensatória da exibição. (HANSEN, 2011, p. 54, tradução nossa)
}

Outra grande contribuição dada por Kracauer para a reflexão sobre cinema encontra-se em Theory of film (1960). O filósofo "procura teorizar o cinema como um modo paradigmático de experimentar, de encontrar e descobrir o mundo na esteira e além dessa crise histórica" (HANSEN, 2011, p. 256, tradução nossa). Nele, o conceito de realismo ganha força, sendo trabalhado dentro do contexto mais amplo desse projeto fenomenológico heurístico.

Kracauer ressignifica seu projeto anterior, iniciado na década de 1920, reafirmando o seu entendimento do cinema enquanto "um novo modo de encontrar 
o mundo, uma experiência perceptiva que afetou e mobilizou o espectador de maneiras sem precedentes" (HANSEN, 2011, p. 262, tradução nossa; ver também GUTFREIND, 2009). Ao mesmo tempo que avança sobre a ideia do filme como um sintoma desse ambiente urbano-industrial historicamente transformado.

\section{Walter Benjamin}

Se a visão pessimista sobre a modernidade e a ênfase na ideologia marcam os escritos de Kracauer, no caso de Benjamin, são outras características que prevalecem. Em relação aos colegas frankfurtianos, Benjamin adotou uma visão mais otimista sobre as transformações da modernidade, talvez por reconhecer a irreversibilidade do processo histórico. Não enfatizou tanto a ideologia, mas sobretudo a tecnologia. A posição adotada pelo filósofo a respeito da tecnologia era, nesse sentido, no mínimo ambivalente, tal como foi a sua posição no tocante à tradição das artes (HANSEN, 2011).

O cinema emerge nesta discussão como a combinação entre tecnologia e arte. Trata-se, para ele, de uma combinação ideal do ponto de vista da estética. O roteiro e a narrativa são outros elementos, desta ordem, sublinhados por Benjamin. Muito por isso, seguindo a leitura de Hansen (2011, p. 79, tradução nossa), o filósofo entende o cinema como o "campo de batalha mais importante da arte e da estética contemporâneas, não por um entusiasmo futurista ou construtivista pela era da máquina, mas porque considerava o filme o único meio que poderia contrariar os efeitos devastadores da humanidade", no contexto de destruição na Primeira Guerra Mundial.

\footnotetext{
A preocupação de Benjamin com o cinema e a mídia tecnológica é inseparável, por um lado, de sua filosofia da história, que gira em torno da questão da modernidade e, por outro, de sua teoria da estética, que engloba tanto a organização da percepção sensorial, historicamente entendido e o destino da arte e da prática artística no sentido mais restrito. Em seus persistentes esforços para inter-relacionar esses domínios, o cinema veio a ser o elo entre as transformações da estética e os impasses da história contemporânea. (HANSEN, 2011, p. 76, tradução nossa)
} 
Todavia o cinema ultrapassa o campo da estética, uma vez que, conforme a visão benjaminiana, ele apresenta função "tanto cognitiva e pedagógica quanto remediadora e terapêutica - na medida em que responde a uma adaptação da tecnologia que já falhou em grande escala e parecia estar caminhando para pior" (HANSEN, 2011, p. 79, tradução nossa).

Em vista do sucesso da mobilização fascista em massa, Benjamin atribuiu ao cinema contemporâneo menos um papel de conscientização do que um papel terapêutico. Como forma de arte de base tecnológica, o cinema oferece a possibilidade de que as psicoses em massa engendradas pela má adaptação industrial-capitalista da tecnologia possam, no mínimo, ser usadas e neutralizadas. Isso acontece com filmes que sacodem o público através de risadas visceralmente experimentadas e coletivas. Nas primeiras versões do ensaio sobre obras de arte, ele desenvolve esse argumento com referência aos filmes de Mickey Mouse, que considerava uma imunização contra psicoses de massa, fantasias sádicas ou delírios masoquistas, na medida em que efetuam uma liberação preventiva de energias inconscientes destrutivas. (HANSEN, 2011, p. 99, tradução nossa)

Em sua reflexão, a audiência do cinema é compreendida como fenômeno coletivo, "que claramente difere das massas da classe trabalhadora assumidas pela esquerda tradicional e pela política trabalhista, bem como da multidão amorfa demonizada pela psicologia das multidões da virada do século" (HANSEN, 2011, p. 96, tradução nossa). Até porque, para Benjamin, o cinema é o exemplo de arte em interação com o espaço coletivo: "a sala de cinema como espaço público, movendo-se como uma forma especificamente moderna, tecnologicamente mediada de experiência sensorial coletiva que distingue mais claramente a recepção de um filme da literatura, do teatro e das belas artes" (HANSEN, 2011, p. 160, tradução nossa).

Isso não quer dizer, no entanto, que Benjamin enxergava as massas contemporâneas como agrupamentos de indivíduos plenamente autônomos: "ele sabia muito bem que a autorrepresentação consciente de classe não era necessariamente a direção na qual as formações dominantes de coletividade estavam indo" (HANSEN, 2011, p. 97, tradução nossa). 
Pelo contrário, o ensaio sobre a obra de arte parte do pressuposto de que as massas não são uma força produtiva intrinsecamente progressiva, mas um problema, se não $o$ problema da política moderna - o ensaio vincula-se à fracassada inervação da tecnologia pela sociedade capitalista e à alienação resultante da percepção coletiva dos sentidos. (HANSEN, 2011, p. 97, tradução nossa, grifo da autora)

O ensaio em questão, $A$ obra de arte na era de sua reprodutibilidade técnica, foi publicado em 1936, quatro anos antes de sua morte. Nele, Benjamin reflete sobre o futuro da arte em meio às consequências da tecnologia. O texto mantém-se certamente como um dos mais comentados nas últimas décadas, em campos diversos das ciências culturais (teoria crítica, história da arte, estudos de cinema, filosofia da estética, cultura visual).

A controvérsia envolvendo o ensaio começou antes mesmo da sua publicação, mais especificamente "a partir do momento em que a segunda versão datilografada (a primeira era um rascunho manuscrito) chegou à mesa de Horkheimer e provocou a resposta substancial de Adorno em 18 de março de 1936" (HANSEN, 2011, p. 83). Já a terceira versão permaneceu em revisão até 1939, entretanto, "apareceu apenas postumamente em Illuminationen (1955), editado por Adorno e Friedrich Podszus. Ali descansou até o final dos anos 1960, quando os escritos de Benjamin foram descobertos pela nova esquerda alemã e pelo movimento estudantil" (HANSEN, 2011, p. 83).

Passadas mais de oito décadas após a primeira publicação, Hansen lança o seguinte questionamento: apesar de toda sua repercussão acadêmica, qual é de fato, se há, qual é a atualidade deste escrito?

Esta questão é inevitável em um momento em que nossas vidas políticas, sociais e pessoais parecem mais do que nunca ser impulsionadas pelo desenvolvimento da tecnologia de mídia e, portanto, por uma transformação acelerada, desintegração e reconfiguração das estruturas da experiência. De fato, se colocarmos a questão da atualidade de Benjamin à luz das tremendas mudanças associadas à tecnologia digital, poderíamos facilmente argumentar que suas teses relativas à mídia tecnológica, em particular seu potencial revolucionário proclamado, pertencem a um período completamente diferente do nosso, e que seus maiores 
prognósticos foram provados errados, no máximo com o advento da consolidação digital e global do capitalismo. Mas chegar a tal conclusão talvez não seja a razão pela qual lemos Benjamin hoje. (HANSEN, 2011, p. 75 , tradução nossa)

Podemos afirmar que um dos tópicos mais discutidos do ensaio se refere à ideia de aura. O tópico abre espaço para diferentes interpretações, desdobrandose em diversos debates. É o caso mais comum, no entanto, da aura ser tratada como categoria primariamente estética: abreviação da autenticidade.

Mesmo na reprodução mais perfeita, um elemento está ausente: o aqui e agora da obra de arte, sua existência única, no lugar em que ela se encontra. É nessa existência única, e somente nela, que se desdobra a história. Essa história compreende não apenas as transformações que ela sofreu, com a passagem do tempo, em sua estrutura física, como as relações de propriedade em que ela ingressou. (BENJAMIN, 1994, p. 167)

Entretanto, para a estudiosa, nem sempre é o caso de avançar com a reflexão sobre aura pelos caminhos da estética. Defende a retomada de um texto mais antigo de Benjamin (2006): On Hashish.

O primeiro comentário de Benjamin sobre o conceito de aura pode ser encontrado em um relatório não publicado sobre um de seus experimentos com haxixe, datado de março de 1930: "Tudo que eu disse sobre $o$ assunto [natureza da aura] foi dirigido polemicamente contra os teosofistas, cuja inexperiência e ignorância que considero altamente repugnante... Primeiro, a aura genuína aparece em todas as coisas, não apenas em certas coisas, como as pessoas imaginam". (HANSEN, 2011, p. 104)

Ou seja, a aura não é qualidade exclusiva de certo objeto ou imagem. Considerar a autenticidade de determinado objeto ou imagem em relação ao seu lugar e tempo no espaço, e pensar que esse ou essa possui qualidade superior (particular), na medida que é única, pois não foi mecanicamente reproduzida, uma vez que nem a tecnologia mais avançada é capaz de reproduzir aquela qualidade. Pensar assim seria apenas mais uma possibilidade de interpretação, diante de muitas outras, do que uma conclusão sobre o conceito. 
Para Hansen, a certeza que deve ser assumida é de que não estamos lidando com um conceito estável, que Benjamin delimitou claramente ao longo de seus escritos. Em vez disso, "descreve um conjunto de significados e relações que aparecem [...] em várias configurações e nem sempre em seu próprio nome; é essa fluidez conceitual que permite que a aura se torne um ponto nodal tão produtivo no pensamento de Benjamin" (HANSEN, 2011, p. 106).

Ao final, respondendo à questão em aberto, a autora julga atualidade no pensamento do filósofo. Embora mantenha o questionamento sobre a validade de seus conceitos e prognósticos particulares, destaca seu esforço para teorizar as transformações da mídia enquanto tecnologia. A teorização de Benjamin deixa duas importantes contribuições, de acordo com ela: 1) o cinema como "meio mais avançado de experiência para se engajar nessa competição ou luta, como um meio tecnológico que tem uma relação ao mesmo tempo metonímica e sensorial-reflexiva com a tecnologia como um todo"; 2) o cinema como meio capaz de nos orientar no presente e no futuro, "no avanço da inervação mimética, não destrutiva de novas tecnologias e, ao mesmo tempo, seu potencial tardio, terapêutico e apotropaico para difundir efeitos patológicos de uma adaptação capitalista-imperialista da tecnologia já fracassada, e que continua a fracassar" (HANSEN, 2011, p. 203-204, tradução nossa).

\section{Theodor W. Adorno}

A relação de Adorno com o cinema difere tanto das relações de Benjamin quanto de Kracauer. O interesse daquele era outro. O filme ocupou, por isso, uma posição marginal em seu trabalho. "Ao contrário da música, com a qual ele estava envolvido como crítico, músico e compositor, o filme permaneceu em sua maior parte uma preocupação teórica" (HANSEN, 2011, p. 208, tradução nossa). Entretanto, isso não é motivo, conforme a estudiosa, para desconsiderar as contribuições de Adorno para a teoria do cinema, a partir da estética. 
econômicas e ideológicas do cinema dentro da indústria cultural, essas reflexões também são inseparáveis de sua filosofia da arte moderna. A própria questão da estética cinematográfica - que, para Adorno não é menor, é a questão de se haveria uma estética do filme - é articulada em termos de padrões desenvolvidos na e pela arte autônoma mais avançada, especialmente a música. (HANSEN, 2011, p. 208, tradução nossa)

Hansen defende que o envolvimento do filósofo com o cinema, mesmo quando indiretamente, isto é, quando teoriza a cultura de massa de modo geral, foi mais profundo do que os estudiosos de cinema costumam supor. Ela resume três fases distintas em que Adorno reflete sobre o assunto. A primeira fase remete de 1925 a 1935, quando datam os escritos publicados no jornal vienense Musikblätter des Anbruch. Ali ele escreveu resenhas e ensaios "sobre cultura popular na forma de 'música leve' e 'kitsch', como a opereta europeia, os sucessos populares e o jazz, bem como a 'música mecânica', que incluía discos de gramofone, rádio e 'os problemas musicais do cinema', silenciosos e sonoros" (HANSEN, 2011, p. 208).

A segunda fase envolve o período de 1935 ao final da década seguinte. Anos em que Adorno passou por Oxford, onde escreveu On Jazz (1936) e On the Fetish-Character of Music and the Regression of Listening (1938), antes de seu exílio nos Estados Unidos, onde permaneceu até 1949. A estudiosa julga que esse foi o período mais produtivo e diversificado do filósofo. Serve de exemplo, inclusive, o seu envolvimento "prático" com o cinema:

Ao mesmo tempo em que elaborava sua crítica da indústria cultural - da Dialética do Esclarecimento a Minima Moralia (1944-47) -, ele estava envolvido com Hollywood e a comunidade cinematográfica em um nível mais pragmático. Um exemplo, trazido à luz, respectivamente, por Gertrud Koch e David Jenemann, é o projeto de filme experimental descrito pela primeira vez no artigo publicado anonimamente Research Project on Anti-Semitism (1941), escrito por Adorno em colaboração com Horkheimer e outros membros do Instituto de Pesquisa Social. Concebido no contexto mais amplo do projeto Studies in Prejudice sob os auspícios do Congresso Judaico Americano, Below the Surface (intitulado The Accident) foi um filme experimental destinado a testar atitudes discriminatórias em relação aos judeus. Embora nunca tenha se materializado além da fase do roteiro, Adorno seguiu o projeto através de várias versões detalhadas de tratamento de 1943 a 1946, com 
contribuições de Kracauer e Hans Richter. Lançado para vários produtores de Hollywood, o projeto ganhou o apoio do roteirista-diretor-produtor de esquerda, Dore Schary, que estava (de vez em quando) no comando da MGM, que também contribuiu com uma versão de tratamento. (HANSEN, 2011, p. 208-209, tradução nossa)

"Outro projeto, mais amplamente conhecido que fez Adorno considerar o cinema em termos estéticos e criativos, foi Composing for the Films ${ }^{2}$, escrito em colaboração com o compositor Hanns Eisler em 1944" (HANSEN, 2011, p. 209). O livro apresenta um relato da natureza da estética, mas também dos aspectos sociológicos da música cinematográfica.

Depois dessas publicações, há a última fase, marcada pelo retorno de Adorno à Alemanha, com o término da Segunda Guerra Mundial.

Essa fase compreende escritos que reiteram e adaptam a crítica da indústria cultural, como seus ensaios sobre televisão (baseados em pesquisa nos Estados Unidos em 1952-53) e Culture Industry Reconsidered (1963), que estende essa crítica à cultura administrativa da República Federal. Mas também inclui esforços para entender o filme no contexto da arte moderna e da estética modernista, dos quais encontramos o relato mais completo de Adorno na Teoria Estética (1970). [Contudo] sua mais extensa declaração sobre a questão da estética cinematográfica continua sendo o ensaio Transparencies on Film (1966). (HANSEN, 2011, p. 209-210)

Ao longo dessa fase, Adorno argumenta que "a dependência do cinema em relação à tecnologia industrial, como meio de reprodução e circulação mecânicas, dominou e impediu o desenvolvimento da técnica artística, entendida como a organização interna do material estético" (HANSEN, 2011, p. 210, tradução nossa). Sua teorização se desenvolve aqui a partir da relação entre técnica artística e tecnologia mecânica:

\footnotetext{
A queixa de Adorno sobre o cinema gira na suposição de que a tecnologia de reprodução impede o desenvolvimento autônomo da técnica cinematográfica, ao invés de, como ele observou em relação à música eletrônica, a técnica artística sendo liberada por possibilidades
} 
tecnológicas. A pergunta aqui - e faz parte do problema que os críticos tiveram com seu argumento sobre o filme - é se ele atribui essa aporia à prática dominante do cinema dentro da indústria cultural ou se ele a localiza no fundamento mecânico do meio cinematográfico como tal. (HANSEN, 2011, p. 215, tradução nossa)

Ou seja, este argumento apresenta a seguinte ameaça: "a predeterminação tecnológica da técnica cinematográfica seria uma circunscrição a priori das possibilidades estéticas do que ele chama de 'filme emancipado'" (HANSEN, 2011, p. 215, tradução nossa). O cerne do problema que ele "enfrenta para uma estética cinematográfica parece ser que a base fotográfica da imagem em movimento privilegia o objeto representacional em detrimento de procedimentos esteticamente autônomos" (HANSEN, 2011, p. 220, tradução nossa).

Mas, consequentemente, seu argumento abre para outra possibilidade de reflexão. Em Transparencies, "Adorno reconsidera o problema da relação entre tecnologia e técnica primariamente como um problema relativo à estética cinematográfica, especificamente com vista ao surgimento do cinema independente na Alemanha Ocidental e nos demais países europeus" (HANSEN, 2011, p. 218, tradução nossa). A seguir, em Teoria Estética, ele "insiste na unidade conceitual de técnica e tecnologia, porque o desenvolvimento da técnica estética interna, como força produtiva, está ligado ao progresso das forças tecnológicas extraestéticas" (HANSEN, 2011, p. 211, tradução nossa).

\footnotetext{
No próprio cinema, os momentos industriais e estético-artesanais divergem sob a pressão socioeconômica. A industrialização radical da arte, a sua adaptação integral aos padrões técnicos alcançados, colidem com o que na arte se recusa à integração. Se a técnica se orienta para o ponto de fuga da industrialização, isso produz-se sempre esteticamente à custa da completa elaboração imanente e, portanto, em detrimento da própria técnica. (ADORNO, 2008b, p. 244)
}

Tal pensamento evidencia, por um lado, a dificuldade de separar técnica e tecnologia (produção artística e produção mecânica, nesta leitura feita pela autora sobre Adorno), por outro lado, atribui ao cinema qualidade específica, e reconhece o seu papel enquanto meio para discutir a arte moderna. 
Ponderando este problema de vários ângulos, ele não apenas concede ao filme um status igual, se excepcional, entre as artes, mas também atribui a ele um papel de liderança na rebelião da arte moderna contra seu próprio status como arte. Em primeiro lugar, porque a prática do cinema independente, mesmo que subsidiada, não pode escapar às pressões do mercado (Hollywood e seus colegas da Alemanha Ocidental) nem à problemática estética de uma arte mecanicamente mediada, Adorno parece disposto a modificar o imperativo de que a arte moderna deve operar no nível mais avançado e diferenciado da técnica. (HANSEN, 2011, p. 218, tradução nossa)

Como resume Hansen, a teorização da estética de Adorno envolve o cinema a partir de duas áreas, que ocupam o centro da obra: a primeira é a arte em geral, seguida da música em específico. A reflexão sobre o cinema surge dentro desse quadro teórico. Ao tratar do cinema, seu pensamento se desenvolve principalmente em relação a técnica (produção artística) e tecnologia (produção mecânica), mas também em relação à "transformação histórica da experiência, imagem e escrita, mimese, beleza natural, tempo e movimento, intermidialidade, coletividade, e a recepção, que ainda contêm impulsos valiosos para a teoria do cinema, análise crítica e prática criativa" (HANSEN, 2011, p. 250, tradução nossa).

\section{Considerações finais}

Hansen explicitou como Kracauer, Benjamin e Adorno contribuíram para uma reflexão crítica sobre cinema, enquanto produção artística e tecnológica nos tempos modernos. Como sua análise mostrou, há pontos de aproximação e distanciamento entre suas obras, embora eles possam estar situados em uma mesma escola alemã. No caso do primeiro, o cinema aparece como tema central. No último, o cinema aparece de modo periférico em relação à arte e à música. Já o caso de Benjamin estaria "a meia distância" entre eles.

Em razão disso, a autora atribui papel de protagonismo a Kracauer, por ser o iniciador da área em estudo e quem, de fato, desenvolveu uma teoria do filme. Ela enfatiza como Kracauer estava verdadeiramente preocupado em refletir a "estética de filme a partir da perspectiva de uma experiência particular e crítica da modernidade" (HANSEN, 2011, p. 6, tradução nossa). 
A modernidade é pensada pelo filósofo como uma "formação altamente ambivalente e contestada, produzida em massa e consumida em massa, na qual o filme e o cinema estavam desempenhando apenas um papel, embora crucial" (HANSEN, 2011, p. 6, tradução nossa). Dentro da cultura de massa, o cinema torna-se "uma forma de autorrepresentação coletiva", bem como "uma matriz ideológica que promove uma identidade social e nacional imaginária" (HANSEN, 2011, p. 66, tradução nossa).

Benjamin trabalha essa relação a partir de outra perspectiva, que é a de "abstração filosófica, senão estética, um correlativo subjetivo das mudanças na organização da percepção na modernidade" (HANSEN, 2011, p. 95, tradução nossa). Em comum, os dois veem que "o fenômeno da massa moderna se manifesta primariamente em atos de consumo e recepção, mediados pelo fetiche da mercadoria" (HANSEN, 2011, p. 95, tradução nossa). "Mas onde a análise de Kracauer se concentra no presente, Benjamin rastreia as origens da cultura de massa no século XIX, notadamente em seu vasto projeto nas arcadas de Paris" (HANSEN, 2011, p. 95, tradução nossa).

Tal como entende o processo histórico, Benjamin ganha maior crédito por sua capacidade criativa de lidar com o problema moderno, que é tecnológico. No que tange ao cinema, "o papel de Benjamin permanece ligado à faculdade mimética, essencial para o seu esforço de teorizar uma inervação imaginativa, não destrutiva, do ambiente tecnológico em constante mudança" (HANSEN, 2011, p. 199 , tradução nossa).

A capacidade de Benjamin de imaginar vastas possibilidades e riscos mortais nas práticas de mídia tecnológica - e apostar em combinações e constelações particulares - torna seu pensamento mais produtivo do que abordagens críticas que, em última análise, possuem viés técnico-utópico ou midiático-pessimista. Hoje, seu legado para a teoria do cinema e da mídia pode consistir, principalmente, nas maneiras pelas quais a estrutura de seu pensamento, seu hábito de pensar em posições antitéticas em suas implicações mais extremas, destaca as contradições na própria cultura da mídia, agora mais do que nunca. (HANSEN, 2011, p. 204, tradução nossa) 
O mérito de Adorno encontra-se no plano da estética. Nessa matéria, Adorno foi além de seus colegas ao elaborar toda uma teoria estética. Estabeleceu, inclusive, relação intelectual de crítica com seu colega: seus apontamentos às teses de Benjamin, às vezes, distorcidos, revelam diferenças importantes. "Contra Benjamin, Adorno também insistiu na importância continuada da arte autônoma, mesmo que a aura pudesse ser compreendida apenas em sua decadência irreversível (ou, na verdade, resistida em suas falsas ressurreições)" (HANSEN, 2011, p. 207, tradução nossa).

Para a estudiosa, o traço comum entre Adorno, Benjamin e Kracauer diz respeito à ideia de pensar o cinema como sintoma da sociedade moderna, em um contexto urbano-industrial. Eles enriqueceram a reflexão crítica sobre cinema, compreendendo-o como "um elemento sintomático dentro de uma estrutura heurística mais ampla, destinada a entender a modernidade e suas tendências de desenvolvimento" (HANSEN, 2011, p. 3, tradução nossa).

\section{Referências}

ADORNO, T. W. Minima moralia. Rio de Janeiro: Azougue, 2008a.

ADORNO, T. W. Teoria estética. Lisboa: Edições 70, 2008b.

ADORNO, T. W. Transparencies on film. Durham: Duke University Press, 1966.

ADORNO, T. W. ; EISLER, H. Composing for the films. Londres: Continuum, 2006.

BENJAMIN, W. A obra de arte na era de sua reprodutibilidade técnica. In: BENJAMIN, Walter. Magia e técnica, arte e política: ensaios sobre literatura e história da cultura. São Paulo: Brasiliense, 1994. p. 159-177. 
BENJAMIN, W. On hashish. Cambridge: Belknap Press, 2006.

GUTFREIND, C. F. Kracauer e os fantasmas da história: reflexões sobre o cinema brasileiro. Comunicação, Mídia e Consumo, São Paulo, v. 6, n. 15, p. 129-144, 2009.

HANSEN, M. B. Babel and babylon. Cambridge: Harvard University Press, 1991.

HANSEN, M. B. Cinema and experience: Siegfried Kracauer, Walter Benjamin, and Theodor W. Adorno. Berkeley: University of California Press, 2011.

HORKHEIMER, M.; ADORNO, T. W. Dialética do esclarecimento. Rio de Janeiro: Zahar, 1985.

KRACAUER, S. From Caligari to Hitler. Princeton: Princeton University Press, 1947.

KRACAUER, S. Theory of film. Princeton: Princeton University Press, 1960.

submetido em: 18 jul. 2019 | aprovado em: 18 set. 2019 